\section{Reply to Lévy et al}

European Journal of Human Genetics (2010) 18, 971; doi:10.1038/ejhg.2010.76; published online 2 June 2010

We thank Lévy et $a l^{1}$ for pointing out the unfortunate inconsistencies in our paper. ${ }^{2}$ The aberrant phasing in our Figure 1 was pointed out to us at an earlier stage by the Jain Foundation and an erratum is being published in parallel (EJHG, this issue). Regarding the mix-up of the oligonucleotides h32DYSF1 and h34DYSF2, we confirm this and have it included in the erratum. It is due to a regrettable mix-up in the ordering procedure. We are pleased to learn that in fact our overall success rate is even better than we initially assumed (at least 78\%), because according to Dr Lévy targeting exon 32 with our antisense oligonucleotide $(\mathrm{AON})$ is also effective. We are in the process of testing the aberrantly named h32DYSF2 (which targets exon 34) to see whether it induces exon 34 skipping.

The authors question the significance of our finding that DYSF exons can be readily skipped using AON design guidelines derived from Duchenne muscular dystrophy (DMD) AONs. ${ }^{3}$ We would like to emphasize that the $D M D$ gene is by no means a regular gene. It is the largest gene in the human genome $(2.2 \mathrm{Mb})$, the coding sequence makes up only $\sim 0.6 \%$ of the gene and thus the introns are exceptionally large. As such, it is conceivable that $D M D$ exon splicing is more reliant on exonic splicing enhancers than other genes, which would make it easier to induce exon skipping targeting exonic sequences. ${ }^{4}$ It remained to be confirmed that this was also the case for other genes and, in fact, one of the major objectives of our study. Our study clearly shows that this appears indeed to be the case, which is an encouraging finding for the exon skipping approach in general.

While analyzing the DYSF gene and dysferlin protein for eligible exons, we have taken a conservative approach. Lévy and colleagues point out that $\mathrm{C} 2$ domains might not be essential for protein function, given the mild phenotypes of the exon 32 deletion patient ${ }^{5}$ and their own patient who only expresses the most C-terminal C2 domain and the transmembrane domain, due to a large homozygous mutation. Nevertheless, there are numerous patients who suffer from splicing mutations that do disrupt domains upstream of the deletion, and who are affected. ${ }^{2}$ Therefore, we felt it was prudent not to assume these domains were redundant, except for the fourth C2 domain, which is deleted in the patient described by Sinnreich et al. ${ }^{5}$ In addition, our priority table is not only based on whether domains were considered essential, but also on the feasibility of correcting mutations. Lévy and colleagues point out that the large homozygous deletion represents a basis for multiple exon skipping targeting $\mathrm{C} 2$ domains. Although this may be true, it would involve skipping not less than five exons simultaneously for the eligible C2 domains. ${ }^{2}$ Here a word of caution is in place. Although it has been shown that therapeutic skipping of two exons (double-exon skipping) is feasible in Duchenne patient- derived cell cultures, ${ }^{6}$ and in vivo in a dog model, ${ }^{7}$ therapeutic tripleexon skipping has thus far only been shown for a Duchenne patient with a duplication of exon 44 , where targeting exon 43 and exon 44 resulted in skipping of exon 43 and both exons $44 .^{8}$ Despite theoretical promise, as set out by us and others, ${ }^{6,9}$ combined skipping of more exons has been proven extremely challenging as yet, in practice. ${ }^{10,11}$ In view of this, we have given a low priority to exons that require multiple (three or more) exons to correct the reading frame.

Finally, although in the absence of patient cell lines we were unable to show that exon skipping of dysferlin leads to restoration of a truncated dysferlin protein product, we felt our findings were of sufficient importance to share with the scientific community. As we discuss in our paper, follow-up research is needed to assess whether exon skipping not only restores production of a truncated dysferlin protein, but more importantly, also leads to (partial) restoration of its function and thus has therapeutic potential for dysferlinopathy patients.

\section{CONFLICT OF INTEREST}

The authors declare no conflict of interest.

Annemieke Aartsma-Rus* and Silvère van der Maarel Department of Human Genetics, Leiden University Medical Center, Leiden, The Netherlands

${ }^{*}$ Correspondence: Dr A Aartsma-Rus, Department of Human Genetics, Leiden University Medical Center, PO Box 9600, 2300 RC Leiden,

The Netherlands.

Tel: +31 71 5269436; Fax: +31 71 5268285;

E-mail:a.m.rus@lumc.nl

1 Lévy N, Wein N, Barthelemy F et al: Therapeutic exon 'switching' for dysferlinopathies? (Letter). Eur J Hum Genet 2010 (E-pub ahead of print 26 May 2010).

2 Aartsma-Rus A, Singh KHK, Fokkema IFAC et al: Therapeutic exon skipping for dysferlinopathies? Eur J Hum Genet 2010 (E-pub ahead of print 10 February 2010).

3 Aartsma-Rus A, van Vliet L, Hirschi $\mathrm{M}$ et al: Guidelines for antisense oligonucleotide design and insight into splice-modulating mechanisms. Mol Ther 2008; 17: 548-553.

4 Aartsma-Rus A, van Ommen GJ: Antisense-mediated exon skipping: a versatile tool with therapeutic and research applications. RNA 2007; 13: 1609-1624.

5 Sinnreich M, Therrien C, Karpati G: Lariat branch point mutation in the dysferlin gene with mild limb-girdle muscular dystrophy. Neurology 2006; 66: 1114-1116.

6 Aartsma-Rus A, Janson AA, Kaman WE et al: Antisense-induced multiexon skipping for Duchenne muscular dystrophy makes more sense. Am J Hum Genet 2004; 74 : 83-92.

7 Yokota T, Azagami S, Abe T et al: Efficacy of systemic morpholino exon-skipping in Duchenne dystrophy dogs. Ann Neurol 2009; 65: 667-676.

8 Aartsma-Rus A, Janson AA, van Ommen GJ et al: Antisense-induced exon skipping for duplications in Duchenne muscular dystrophy. BMC Med Genet 2007; 8: 43.

9 Beroud C, Tuffery-Giraud S, Matsuo M et al: Multiexon skipping leading to an artificial DMD protein lacking amino acids from exons 45 through 55 could rescue up to $63 \%$ of patients with Duchenne muscular dystrophy. Hum Mutat 2007; 28: 196-202.

10 Aartsma-Rus A, Kaman WE, Weij R et al: Exploring the frontiers of therapeutic exon skipping for Duchenne muscular dystrophy by double targeting within one or multiple exons. Mol Ther 2006; 14: 401-407.

11 van Vliet L, De Winter CL, van Deutekom JC et al: Assessment of the feasibility of exon 45-55 multiexon skipping for Duchenne muscular dystrophy. BMC Med Genet 2008; 9: 105 . 